\title{
Gynecological organ involvement at robot-assisted radical cystectomy in females: Is anterior exenteration necessary?
}

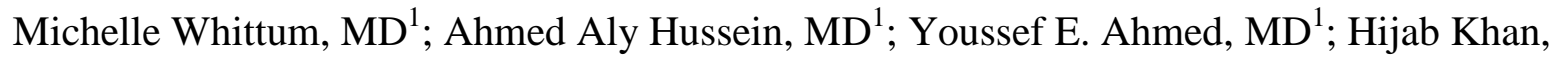
$\mathrm{MD}^{1}$; Collin Krasowski, MD ${ }^{1}$; Neil B. Huben, $\mathrm{MD}^{1}$; Paul R. May, MD ${ }^{1}$; Tomoaki Terakawa, $\mathrm{MD}^{2}$; Qiang Li, MD ${ }^{1}$; Khurshid A. Guru, $\mathrm{MD}^{1}$

${ }^{1}$ Department of Urology, Roswell Park Cancer Institute, Buffalo, NY, United States; ${ }^{2}$ Department of Urology, Kobe University Graduate School of Medicine, Kobe, Japan

Funding: This research was supported in part by funding from the National Cancer Institute of the National Institutes of Health under award number: R25CA181003, and Roswell Park Alliance Foundation.

Cite as: Can Urol Assoc J 2018 May 14; Epub ahead of print. http://dx.doi.org/10.5489/cuaj.5086

Published online May 14, 2018

$* * *$

\section{Abstract}

Introduction: We aimed to investigate patient and disease variables associated with gynecological organ invasion in females with bladder cancer at the time of robot-assisted radical cystectomy (RARC).

Methods: We conducted a retrospective review of female patients who underwent robot-assisted anterior pelvic exenteration (RAAE) between 2005 and 2016. Patients were divided into two groups: those with gynecological organ involvement at RAAE and those without. Data were reviewed for perioperative and pathological outcomes. Kaplan-Meier method was used to depict survival outcomes. Multivariable stepwise regression analysis was performed to identify predictors of gynecological organ involvement.

Results: A total of 118 female patients were identified; 17 (14\%) showed evidence of gynecological organ invasion at RAAE. Patients with gynecological organ invasion had more lymphovascular invasion at transurethral resection of bladder tumour (TURBT) (82\% vs. 46\%; $\mathrm{p}=0.006)$, trigonal tumours at TURBT (59\% vs. $18 \%$; $\mathrm{p}=0.001)$, multifocal disease (65\% vs. $33 \%$; $=0.01), p N+(71 \%$ vs. 22\%; $p<0.001)$, positive surgical margins ( $24 \%$ vs. $4 \% ; \mathrm{p}=0.02$ ), and they less commonly demonstrated pure urothelial carcinoma at TURBT (18\% vs. 66\%; $\mathrm{p}<0.001)$. On multivariate analysis, significant predictors of gynecological organ invasion were pN positive disease (odds ratio [OR] 6.48; 95\% confidence interval [CI] 1.64-25.51; p=0.008), trigonal tumour location (OR 5.72; 95\% CI 1.39-23.61; $\mathrm{p}=0.02$ ), and presence of variant histology (OR18.52; 95\% CI 3.32-103.4; p=0.001). 
Conclusions: Patients with trigonal tumours, variant histology, and nodal involvement are more likely to have gynecological organs invasion at RAAE. This information may help improve counselling of patients and better identify candidates for gynecological organ-sparing cystectomy.

\section{Introduction}

The gold standard for treatment of females with muscle invasive bladder cancer (MIBC) and refractory non-muscle invasive disease is anterior pelvic exenteration [1]. Robot-assisted radical cystectomy (RARC) has been increasingly utilized, as it provides equivalent oncologic outcomes to the conventional open approach, and provides superior perioperative outcomes in terms of less blood loss, transfusion rates and improved convalescence [2]. Robot-assisted anterior pelvic exenteration (RAAE) has been shown feasible and reproducible[3].

Recently, there has been growing interest in sparing the gynecologic pelvic organs at radical cystectomy (RC) to minimize adverse health-related quality of life (HRQoL) consequences, especially for younger patients. Prior studies have shown that anterior exenteration may pose a negative impact on females regardless of their age. Removing gynecologic organs can cause early menopause, increasing risk of osteoporosis and or the need for hormone replacement therapy (HRT), which may increase risk of breast cancer $[4,5]$. Additionally, women may experience worse self-perceived body-image, more difficulties adapting to life, and decreased social functioning [6]. It also precludes female patients from future child bearing and adversely impacts their sexual lives.

Prior studies have investigated the prevalence of gynecologic organ involvement at the time of open RC, with an estimated incidence of 3-8\% [7-9]. Despite the relatively low incidence, utilization of gynecologic organ sparing surgeries remains limited. In this context, we aimed to investigate the prevalence of tumor invasion into adjacent gynecologic organs, and identify predictors for gynecologic organs involvement at RAAE, which may improve risk stratification and allow better counselling for patients who wish for gynecologic organ sparing surgery.

\section{Methods}

We retrospectively reviewed our prospectively maintained RARC quality assurance database (2005-2016) performed by a single surgeon (K.A.G.) at Roswell Park Cancer institute. All patients had RARC with curative intent, and had non-metastatic disease on preoperative work up. Data were analyzed for demographics (age, body mass index [BMI], American Society of Anesthesiologists [ASA] score), preoperative disease-specific characteristics (neoadjuvant chemotherapy, prior abdominal/pelvic surgery, and prior radiation), operative variables (type and technique of urinary diversion; operative time, estimated blood loss [EBL] ), and postoperative outcomes (adjuvant chemotherapy, hospital stay, intensive care unit [ICU] stay, complication, readmissions, mortality, and follow up). All female patients were treated with RAAE, with surgical technique previously described $[10,11]$. Additional disease specific parameters were 
collected from final pathology and most recent transurethral resection of the bladder tumor (TURBT) reports (tumor site, TNM staging, tumor grade, histological type, and lymphovascular invasion [LVI]).

Female patients were identified and divided into 2 groups: those with gynecologic organ involvement at RAAE and those without. Univariable associations between baseline characteristics and outcome measurements were statistically assessed using Fisher exact test for categorical and Wilcoxon Rank Sum test for continuous variables. Stepwise multivariate logistic regression models were fit to evaluate preoperative, operative, postoperative and pathologic predictors of gynecological organs invasion. All statistical analyses were performed using SAS software (version 9.3, SAS Institute Inc., Cary, NC). All tests were two-side, with statistical significance defined as $\mathrm{p} \leq 0.05$.

\section{Results}

118 female patients underwent RAAE between 2005 and 2016, of whom 17 (14\%) exhibited direct tumor invasion into their gynecologic organs. Both groups were comparable in terms of preoperative and operative variables. There was no statistically significant difference between the two groups in terms of hospital or ICU stay, complications, readmissions, mortality at 30 and 90 days. Patients who had gynecologic organ invasion received adjuvant chemotherapy more frequently ( $41 \%$ vs $9 \%, \mathrm{p}=0.002$ ) (Table 1 ). They more frequently demonstrated positive pelvic lymph nodes ( $\mathrm{pN}+$ ) ( $71 \%$ vs $22 \%$, $\mathrm{p}<0.001)$, LVI ( $82 \%$ vs $46 \%$, $\mathrm{p}=0.006)$ ), positive surgical margins ( $24 \%$ vs $4 \%$, $\mathrm{p}=0.02$ ), variant/mixed histology tumors ( $83 \%$ vs $34 \%$, $\mathrm{p}<0.001$ ), trigonal tumor location ( $59 \%$ vs. $18 \% \mathrm{p}=0.001)$ and multifocal tumors ( $65 \%$ vs. $33 \% \mathrm{p}=0.01)$. Vaginal involvement was the most common site for female organ involvement $(\mathrm{n}=13,76 \%)$ followed by the uterus ( $\mathrm{n}=7,41 \%)$ (Table 2). On multivariate analysis, significant predictors of gynecologic organ invasion were $\mathrm{pN}+(\mathrm{OR} 6.48,95 \% \mathrm{CI} 1.64-25.51, \mathrm{p}=0.008)$, trigonal tumor location on TURBT (OR 5.72, 95\% CI 1.39-23.61, $\mathrm{p}=0.02$ ), and presence of variant histology on TURBT (OR 18.52, 95\% CI 3.32-103.4, $\mathrm{p}=0.001$ ) (Table 3).

\section{Discussion}

The past decade has witnessed a dramatic increase in the utilization of RARC ( $<1$ to $>13 \%$ ) [12]. However, studies from the open RC literature have demonstrated the feasibility and safety of gynecologic organ preservation at RC, with paucity of studies investigating the prevalence of female organ involvement at RAAE (Table 4). Potential advantages of such an approach include avoidance of early menopause, especially in younger patients, which may pose an increased risk of cardiovascular disease and accelerated bone loss. While long-term HRT can combat these outcomes, it has been associated with long-term risk of breast cancer [4, 5]. For patients of childbearing age, removing the uterus and adnexa precludes them from future pregnancies; it is important to note that studies have demonstrated that pregnancy is safe after gynecologic organ sparing cystectomy [13, 14]. Such benefits are not limited to pre-menopausal women. Ali-ElDein et al suggested that by preserving the reproductive organs, there is less damage to the pelvic 
fascia, thereby reducing the risk of pelvic floor prolapse [15]. Additionally, in patients who underwent neobladders, the risk of neobladder-vaginal fistula is significantly diminished even with only sparing the anterior vaginal wall [16]. From a quality of life standpoint, negative impacts of anterior exenteration have been studied and well documented. In a retrospective cohort of 62 patients who underwent anterior pelvic exenteration, Roos et al found that more physical, sexual and social problems were reported. Specifically, younger women in the study experienced greater difficulty adapting to daily life, and experienced worse body image, and adversely impacted their sexual lives [6]. In the same context, a more recent study found that the construction of a neovagina has been associated with better self-confidence, and allowed resumption of sexual function $[17,18]$.

Despite the benefits of gynecologic organ sparing surgery, the question remains whether oncologic outcomes are in turn compromised. The largest cohort of patients who underwent uterus-, fallopian tube-, ovary-, and vagina sparing cystectomy followed by U-shaped ileal neobladder construction included 30 women, of whom nine died from bladder cancer, one patient had local recurrence, and five patients experienced disseminated disease. One-third of the patients had extravesical disease and DSS was $70 \%$ at 5 years [19]. These findings highlight the need for identification of better selection criteria for patients undergoing gynecologic organ sparing surgeries. Menon et al published a series of 3 cases that underwent robot-assisted gynecologic organ sparing RC, but they did not report their relapse rates or survival [20]. The prevalence of gynecologic organ invasion in our study is $14 \%$, which is higher than previously reported [7, 8]. Ali-El-Dein et al attempted to identify predictors of gynecologic organ involvement at RC in a cohort of 609 women who underwent open anterior exenteration. They found that the risk of the genital organ involvement was low, with only 16 patients (3\%) experiencing gynecologic organ invasion. Gynecologic organ involvement was more frequent with high grade tumors and urothelial cell type cancers [21]. In a similar study that included 54 women, only 3 (6\%) patients experienced gynecologic organ involvement, however, they were unable to find any predictors of gynecologic organ involvement likely because of the small patient cohort [8]. We also observed a similar pattern of prior gynecologic organ involvement, where the vagina is the most common site involved [9].

We found that $\mathrm{pN}$ positive disease, trigonal tumor location at TURBT, and presence of variant histology at TURBT were significant predictors of gynecologic organ invasion at RAAE. The adverse impact of $\mathrm{pN}$ positive status and the presence of variant histology on oncologic outcomes have been previously described [22].The trigonal location may be associated with gynecologic organ invasion, given the anatomical proximity to the vagina posteriorly. Tumor location and presence of variant histology can be known preoperatively as part of clinical staging, and therefore can be used for better counselling of patients about the feasibility of genital sparing surgery.

Although the vast majority of female patients do not have gynecologic organ invasion at anterior pelvic exenteration, currently, the decision to perform a gynecologic sparing procedure 
is mainly based on patient and surgeon preferences. Surgeons usually rely on clinical staging (prior TURBT's and/or imaging studies) to determine the eligibility of patients for such procedure. Identifying factors associated with gynecologic organ involvement may help improve risk-stratification, and identify women who can safely undergo gynecologic organ sparing surgery rather than depriving all women of maintaining their gynecologic organs upon cystectomy. Higher risk women would continue to undergo radical surgery, given the adverse impact of disease stage on disease outcomes.

Despite the uniqueness of this study, several limitations exist. The retrospective study design has its recognized limitations. This is a single institution study; therefore generalization of the results may not be appropriate. In spite of the relatively small cohort of patients, to the best of our knowledge, this is the largest series of female patients with gynecologic organs invasion that has been reported after RAAE.

\section{Conclusion}

Trigonal tumor location and presence of variant histology at TURBT were significantly associated with gynecologic organ involvement in female patients at robot-assisted anterior pelvic exenteration. These results may help improve risk stratification and better identify candidates for gynecologic organ sparing cystectomy.

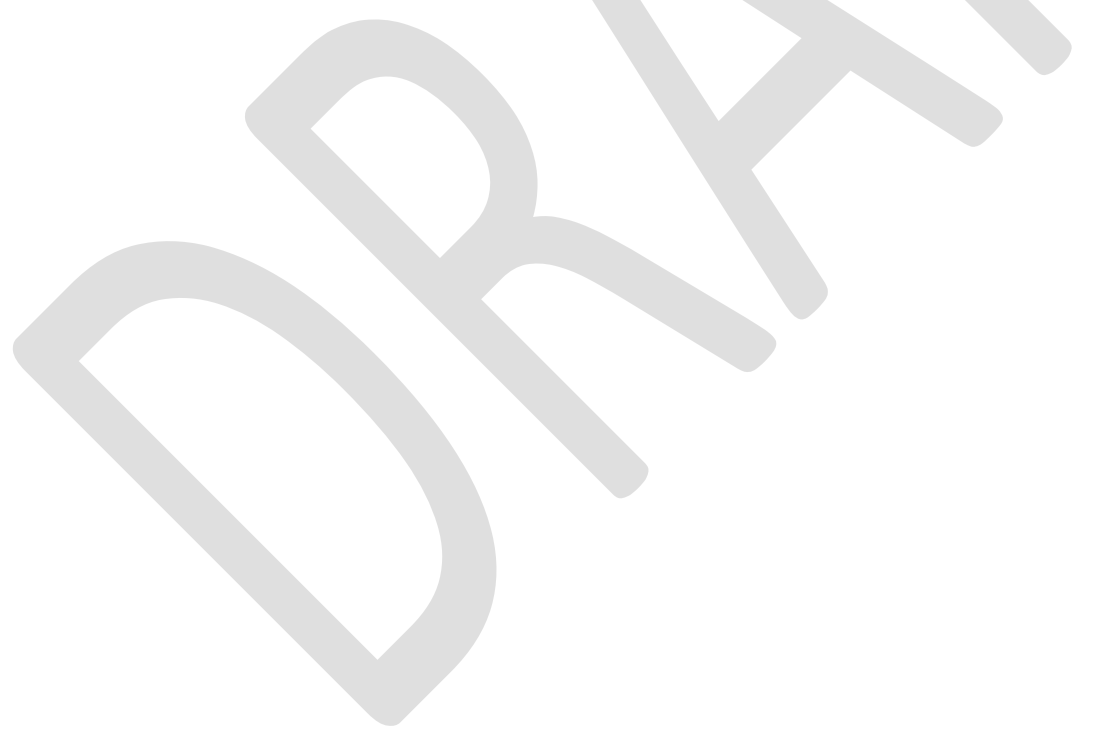




\section{References}

1. Alfred Witjes J, Lebret T, Compérat EM, Cowan NC, De Santis M, Bruins HM, et al. Updated 2016 EAU Guidelines on Muscle-invasive and Metastatic Bladder Cancer. European urology. 2017;71:462-75.

2. Wilson TG, Guru K, Rosen RC, Wiklund P, Annerstedt M, Bochner BH, et al. Best practices in robot-assisted radical cystectomy and urinary reconstruction: recommendations of the Pasadena Consensus Panel. Eur Urol. 2015;67:363-75.

3. K.A. HAAAYEG. Robot-Assisted Radical Cystectomy in Female- Anterior Exenteration: The "Technique of Spaces”: Springer International Publishing.; 2017.

4. Marsden J. Hormone-replacement therapy and breast cancer. Lancet Oncol. 2002;3:30311.

5. Shuster LT, Rhodes DJ, Gostout BS, Grossardt BR, Rocca WA. Premature menopause or early menopause: long-term health consequences. Maturitas. 2010;65:161-6.

6. Roos EJ, de Graeff A, van Eijkeren MA, Boon TA, Heintz AP. Quality of life after pelvic exenteration. Gynecol Oncol. 2004;93:610-4.

7. Ali-El-Dein B, Abdel-Latif M, Mosbah A, Eraky I, Shaaban AA, Taha NM, et al. Secondary malignant involvement of gynecologic organs in radical cystectomy specimens in women: is it mandatory to remove these organs routinely? J Urol. 2004;172:885-7.

8. Varkarakis IM, Pinggera G, Antoniou N, Constantinides K, Chrisofos M, Deliveliotis C. Pathological review of internal genitalia after anterior exenteration for bladder cancer in women. Evaluating risk factors for female organ involvement. Int Urol Nephrol. 2007;39:1015-21.

9. Djaladat H, Bruins HM, Miranda G, Cai J, Skinner EC, Daneshmand S. Reproductive organ involvement in female patients undergoing radical cystectomy for urothelial bladder cancer. J Urol. 2012;188:2134-8.

10. Azzouni FS, Din R, Rehman S, Khan A, Shi Y, Stegemann A, et al. The first 100 consecutive, robot-assisted, intracorporeal ileal conduits: evolution of technique and 90day outcomes. Eur Urol. 2013;63:637-43.

11. Hussein AA, Ahmed YE, Kozlowski JD, May PR, Nyquist J, Sexton S, et al. Robotassisted approach to 'W'-configuration urinary diversion: a step-by-step technique. BJU Int. 2017;120:152-7.

12. Leow JJ, Reese SW, Jiang W, Lipsitz SR, Bellmunt J, Trinh QD, et al. Propensitymatched comparison of morbidity and costs of open and robot-assisted radical cystectomies: a contemporary population-based analysis in the United States. Eur Urol. 2014;66:569-76.

13. Barrett RJ, 2nd, Peters WA, 3rd. Pregnancy following urinary diversion. Obstet Gynecol. 1983;62:582-6. 
14. Volkmer BG, Seidl EM, Gschwend JE, de Petriconi R, Bach D, Kleinschmidt K. Pregnancy in women with ureterosigmoidostomy. Urology. 2002;60:979-82.

15. Ali-El-Dein B, Gomha M, Ghoneim MA. Critical evaluation of the problem of chronic urinary retention after orthotopic bladder substitution in women. J Urol. 2002;168:58792.

16. Blute ML, Gburek BM. Continent orthotopic urinary diversion in female patients: early Mayo Clinic experience. Mayo Clin Proc. 1998;73:501-7.

17. Corney RH, Crowther ME, Everett H, Howells A, Shepherd JH. Psychosexual dysfunction in women with gynaecological cancer following radical pelvic surgery. $\mathrm{Br} \mathrm{J}$ Obstet Gynaecol. 1993;100:73-8.

18. Gleeson N, Baile W, Roberts WS, Hoffman M, Fiorica JV, Barton D, et al. Surgical and psychosexual outcome following vaginal reconstruction with pelvic exenteration. Eur J Gynaecol Oncol. 1994;15:89-95.

19. Koie T, Hatakeyama S, Yoneyama T, Hashimoto Y, Kamimura N, Ohyama C. Uterus-, fallopian tube-, ovary-, and vagina-sparing cystectomy followed by U-shaped ileal neobladder construction for female bladder cancer patients: oncological and functional outcomes. Urology. 2010;75:1499-503.

20. Menon M, Hemal AK, Tewari A, Shrivastava A, Shoma AM, Abol-Ein H, et al. Robotassisted radical cystectomy and urinary diversion in female patients: technique with preservation of the uterus and vagina. J Am Coll Surg. 2004;198:386-93.

21. Ali-El-Dein B, Mosbah A, Osman Y, El-Tabey N, Abdel-Latif M, Eraky I, et al. Preservation of the internal genital organs during radical cystectomy in selected women with bladder cancer: a report on 15 cases with long term follow-up. Eur J Surg Oncol. 2013;39:358-64.

22. Raza SJ, Wilson T, Peabody JO, Wiklund P, Scherr DS, Al-Daghmin A, et al. Long-term oncologic outcomes following robot-assisted radical cystectomy: results from the International Robotic Cystectomy Consortium. Eur Urol. 2015;68:721-8. 
Figures and Tables

Fig. 1.

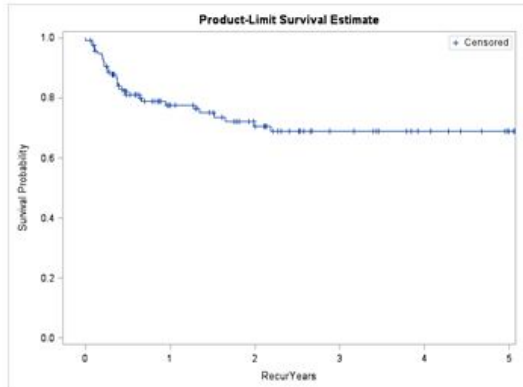

DSS

\begin{tabular}{|l|l|l|l|l|}
\hline Year & 1 & 2 & 3 & 5 \\
\hline $\begin{array}{l}\text { Patients at } \\
\text { risk }\end{array}$ & 118 & 69 & 50 & 24 \\
\hline Death & 13 & 1 & 2 & 0 \\
\hline $\begin{array}{l}\text { Survival } \\
\text { Rate }\end{array}$ & 89 & 88 & 84 & 84 \\
\hline
\end{tabular}

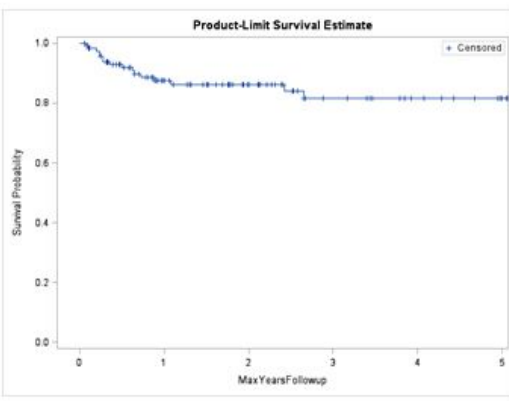

RFS

\begin{tabular}{|l|l|l|l|l|}
\hline Year & 1 & 2 & 3 & 5 \\
\hline $\begin{array}{l}\text { Patients at } \\
\text { risk }\end{array}$ & 118 & 63 & 45 & 21 \\
\hline Death & 24 & 5 & 1 & 0 \\
\hline $\begin{array}{l}\text { Survival } \\
\text { Rate }\end{array}$ & 80 & 73 & 72 & 72 \\
\hline
\end{tabular}

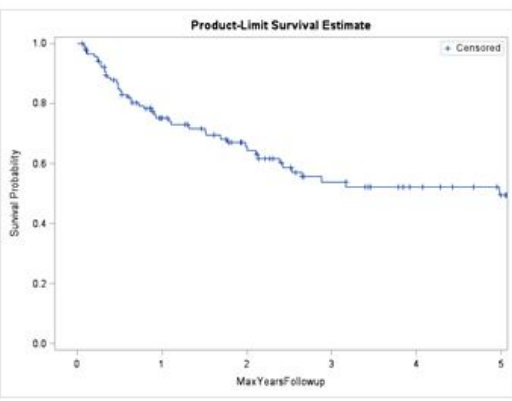

OS

\begin{tabular}{|l|l|l|l|l|}
\hline Year & 1 & 2 & 3 & 5 \\
\hline $\begin{array}{l}\text { Patients at } \\
\text { risk }\end{array}$ & 118 & 69 & 50 & 24 \\
\hline Death & 27 & 8 & 8 & 1 \\
\hline $\begin{array}{l}\text { Survival } \\
\text { Rate }\end{array}$ & 77 & 68 & 55 & 53 \\
\hline
\end{tabular}




\begin{tabular}{|c|c|c|c|}
\hline Variable & $\begin{array}{l}\text { No gynecological } \\
\text { organ invasion }\end{array}$ & $\begin{array}{l}\text { Gynecological } \\
\text { organ invasion }\end{array}$ & $\mathbf{p}$ \\
\hline Number of patients, n (\%) & $101(85)$ & $17(14)$ & N/A \\
\hline \multicolumn{4}{|l|}{ Preoperative characteristics } \\
\hline Age at cystectomy, mean (SD) (years) & $69(11)$ & $71(10)$ & 0.51 \\
\hline BMI, mean $(\mathrm{SD})\left(\mathrm{kg} / \mathrm{m}^{2}\right)$ & $28(6)$ & $28(6)$ & 0.95 \\
\hline ASA score $\geq 3, \mathrm{n}(\%)$ & $55(57)$ & $13(76)$ & 0.14 \\
\hline Prior abdominal/pelvic surgery, n (\%) & $77(77)$ & $10(63)$ & 0.23 \\
\hline Prior radiation, n (\%) & $2(2)$ & 0 & 1.00 \\
\hline Neoadjuvant chemotherapy, n (\%) & $17(17)$ & $6(35)$ & 0.10 \\
\hline \multicolumn{4}{|l|}{ Operative outcomes } \\
\hline Type of diversion, ileal conduit, n (\%) & $89(88)$ & $17(100)$ & 0.45 \\
\hline $\begin{array}{l}\text { Technique of diversion, intracorporeal, } n \\
(\%)\end{array}$ & $68(67)$ & $13(76)$ & 0.45 \\
\hline Operative time, median (IQR) (minutes) & $370(300-448)$ & $356(315-393)$ & 0.55 \\
\hline Estimated blood loss, mean (SD) (ml) & $300(110-500)$ & $250(113-475)$ & 0.96 \\
\hline \multicolumn{4}{|l|}{ Postoperative outcomes } \\
\hline Adjuvant chemotherapy, n (\%) & $9(9)$ & $7(41)$ & 0.002 \\
\hline Hospital stay, median (IQR) (days) & $9(7-12)$ & $9(7-9)$ & 0.54 \\
\hline ICU stay, median (IQR) (days) & $1(1-2)$ & $1(1-2)$ & 0.65 \\
\hline 30-days overall complications, n (\%) & $51(51)$ & $8(47)$ & 0.79 \\
\hline 30-day high-grade complications, n (\%) & $18(18)$ & $2(12)$ & 0.73 \\
\hline 90-day overall complications, n (\%) & $63(62)$ & $10(59)$ & 0.78 \\
\hline 90-day high-grade complications, n (\%) & $23(23)$ & $2(12)$ & 0.52 \\
\hline 30-day readmissions, n (\%) & $19(19)$ & $2(12)$ & 0.73 \\
\hline 90-days readmissions, n (\%) & $29(29)$ & $3(18)$ & 0.56 \\
\hline 30-day mortality, n (\%) & 0 & 0 & 1.00 \\
\hline 90-day mortality, n (\%) & $6(6)$ & $1(6)$ & 1.00 \\
\hline Followup, median (IQR) (months) & $23(8-45)$ & $9(6-13)$ & 0.03 \\
\hline
\end{tabular}

ASA: American Society of Anesthesiologists; BMI: body mass index; ICU: intensive care unit; IQR: interquartile range; RAAE: robot-assisted anterior pelvic exenteration; SD: standard deviation. 


\begin{tabular}{|c|c|c|c|}
\hline Variable & $\begin{array}{l}\text { No gynecological } \\
\text { organ invasion }\end{array}$ & $\begin{array}{c}\begin{array}{c}\text { Gynecological organ } \\
\text { invasion }\end{array} \\
\end{array}$ & $\mathbf{p}$ \\
\hline Number of patients, $\mathrm{n}(\%)$ & $101(85)$ & $17(14)$ & NA \\
\hline \multicolumn{4}{|l|}{ TURBT findings } \\
\hline Lymphovascular invasion, n (\%) & $42(46)$ & $14(82)$ & 0.006 \\
\hline Positive surgical margins, n (\%) & $4(4)$ & $4(24)$ & 0.02 \\
\hline $\begin{array}{l}\text { Pure urothelial cell carcinoma, } n \\
(\%)\end{array}$ & $67(66)$ & $3(18)$ & $<0.001$ \\
\hline $\begin{array}{l}\text { Urothethlial mixed carcinoma, } n \\
(\%)\end{array}$ & $27(27)$ & $12(71)$ & $<0.001$ \\
\hline Non-urothethlial carcinoma, n (\%) & $7(7)$ & $2(12)$ & 0.62 \\
\hline \multicolumn{4}{|l|}{ Tumour location at TURBT } \\
\hline Lateral wall, n (\%) & $63(63)$ & $14(83)$ & 0.11 \\
\hline Posterior wall, n (\%) & $39(39)$ & $10(59)$ & 0.12 \\
\hline Trigone, n (\%) & $18(18)$ & $10(59)$ & 0.001 \\
\hline Dome of the bladder, $\mathrm{n}(\%)$ & $20(20)$ & $2(12)$ & 0.74 \\
\hline Anterior wall, n (\%) & $31(31)$ & $6(35)$ & 0.71 \\
\hline Multifocal, n (\%) & $33(33)$ & $11(65)$ & 0.01 \\
\hline \multicolumn{4}{|c|}{ Gynecological organ involvement at RAAE } \\
\hline Vagina, n (\%) & \multirow{4}{*}{ N/A } & $13(76)$ & - \\
\hline Cervix, n (\%) & & $1(6)$ & - \\
\hline Uterus, n (\%) & & $7(41)$ & - \\
\hline Adnexa, n (\%) & & $6(35)$ & - \\
\hline Perivascular fat, n (\%) & $31(31)$ & $4(24)$ & 0.55 \\
\hline \multicolumn{4}{|l|}{ Pathology after RAAE } \\
\hline Lymph node yield, mean (SD) & $21(11)$ & $20(12)$ & 0.63 \\
\hline Positive lymph nodes, n (\%) & $22(22)$ & $12(71)$ & $<0.001$ \\
\hline
\end{tabular}

RAAE: robot-assisted anterior pelvic exenteration; SD: standard deviation; TURBT:

transurethral resection of bladder tumour.

Table 3. Univariate and multivariate stepwise logistic regression models for predictors of gynecological organ invasion 


\begin{tabular}{|l|c|c|c|c|c|c|}
\hline \multirow{2}{*}{ Variable } & \multicolumn{3}{|c|}{ Univariate } & \multicolumn{3}{|c|}{ Multivariate } \\
\cline { 2 - 8 } & OR & $\mathbf{9 5 \%}$ CI & $\mathbf{p}$ & OR & $\mathbf{9 5 \%}$ CI & p \\
\hline Lymph node yield & 0.99 & $0.95,1.04$ & 0.74 & & & \\
\hline Positive lymph nodes (N-) & 8.62 & $2.74,27.09$ & $<0.001$ & 6.48 & $1.64,25.51$ & 0.008 \\
\hline Lymphovascular invasion & 5.44 & $1.46,20.24$ & 0.01 & & & \\
\hline $\begin{array}{l}\text { Positive surgical margins } \\
\text { (negative) }\end{array}$ & 7.46 & $1.66,33.51$ & 0.009 & & & \\
\hline Variant histology (pure urethelial) & 9.20 & $2.47,34.2$ & 0.001 & $\begin{array}{c}18.5 \\
2\end{array}$ & $3.32,103.4$ & 0.001 \\
\hline Perivesicular fat invasion & 0.70 & $1.29,2.30$ & 0.02 & & & \\
\hline Multifocal tumour & 3.78 & $1.29,11.10$ & 0.02 & & & \\
\hline Tumor location & & & & & & \\
\hline \multicolumn{1}{|c|}{ Trigone } & 6.59 & $2.21,19.63$ & $<0.001$ & 5.72 & $1.39,23.61$ & 0.02 \\
\hline \multicolumn{1}{|c|}{ Dome } & 0.54 & $0.11,2.56$ & 0.65 & & & \\
\hline \multicolumn{1}{|c|}{ Lateral wall } & 2.82 & $0.76,10.43$ & 0.12 & & & \\
\hline Anterior wall & 1.23 & $0.42,3.63$ & 0.36 & & & \\
\hline \multicolumn{1}{|c|}{ Posterior wall } & 2.27 & $0.80,6.46$ & 0.12 & & & \\
\hline
\end{tabular}

CI: confidence interval; OR: odds ratio. 
Table 4. Review of prior studies investigation gynecologic organ sparing cystectomies ${ }^{22}$

\begin{tabular}{|c|c|c|c|c|c|c|c|c|c|}
\hline Reference & Pts, n & $\begin{array}{c}\text { FU } \\
\text { median* } \\
\text { (IQR) }\end{array}$ & $\begin{array}{l}\text { T stage } \\
\geq 3(\%)\end{array}$ & $\begin{array}{l}\text { Positive } \\
\text { surgical } \\
\text { margins }\end{array}$ & $\begin{array}{c}\text { Local } \\
\text { reoccurrence }\end{array}$ & $\begin{array}{c}\text { Distant } \\
\text { recurrence }\end{array}$ & $\begin{array}{c}\text { Disease- } \\
\text { specific } \\
\text { mortality } \\
(\%) \\
\end{array}$ & $\begin{array}{l}\text { DSS } \\
(\%)\end{array}$ & $\begin{array}{l}\text { OS } \\
(\%)\end{array}$ \\
\hline \multicolumn{10}{|l|}{ Open approach } \\
\hline $\begin{array}{l}\text { Ali-El-Dein } \\
\text { et al }(2013)^{20}\end{array}$ & 15 & $\begin{array}{c}72 \\
(37-99) \\
\end{array}$ & $15(100 \%)$ & NR & $1(6.7 \%)$ & $2(13 \%)$ & $3(20 \%)$ & $\begin{array}{l}\text { 5-yr: } \\
80 \%\end{array}$ & $\begin{array}{l}\text { 5-yr: } \\
80 \%\end{array}$ \\
\hline $\begin{array}{l}\text { Horenblas et } \\
\text { al }(2001)^{23}\end{array}$ & 3 & $\begin{array}{c}42 \\
(24-72)\end{array}$ & $1(7.7 \%)$ & NR & 0 & 0 & 0 & NR & NR \\
\hline Koie $(2010)^{18}$ & 30 & $\begin{array}{c}41 \\
(4-98)\end{array}$ & $\begin{array}{c}10 \\
(33.3 \%)\end{array}$ & $0 \%$ & $1(3.3 \%)$ & 5 (16.7) & $9(30 \%)$ & $\begin{array}{l}\text { 5-yr: } \\
70 \%\end{array}$ & NR \\
\hline $\begin{array}{l}\text { Kulkarni et al } \\
(2008)^{24}\end{array}$ & 14 & $\begin{array}{c}24.5 \\
(12-65)\end{array}$ & - & NR & $1(7 \%)$ & $1(7 \%)$ & $2(14 \%)$ & NR & NR \\
\hline $\begin{array}{l}\text { Wishahi et al } \\
(2015)^{25}\end{array}$ & 13 & $\begin{array}{c}132 \\
(80-180)\end{array}$ & $3(23 \%)$ & $0 \%$ & NR & NR & NR & $\begin{array}{c}\text { 5-yr: } \\
100 \% \\
10-y r: \\
62 \% \\
\end{array}$ & $\begin{array}{c}\text { 5-yr: } \\
100 \% \\
10-y r: \\
62 \% \\
\end{array}$ \\
\hline \multicolumn{10}{|c|}{ Robot-assisted approach } \\
\hline $\begin{array}{l}\text { Menon et al } \\
(2004)^{19}\end{array}$ & 3 & NR & $3(100 \%)$ & 0 & & NR & NR & NR & NR \\
\hline
\end{tabular}

*Followup period is measured in months. DSS: disease-specific survival; FU: followup; NR: not reported; OS: overall survival; pts: patients. 